\title{
Necrose Pelvi-Perineal Pós-Radioterapia para Câncer de Próstata: Relato de Caso
}

\section{Perineal Necrosis Following Radiotherapy for Prostate Cancer: Case Report}

\author{
PAULO GUSTAVO KOTZE ${ }^{1}$; JULIANAFERREIRAMARTINS ${ }^{2}$; GUILHERME VASCONCELOS SELLA ${ }^{3}$; \\ JULIANAGONÇALVES ROCHA ${ }^{4}$; ERONFÁBIO MIRANDA ${ }^{5}$
}

\author{
${ }^{1}$ Chefe do Serviço de Coloproctologia do Hospital Universitário Cajuru - PUCPR; ${ }^{2}$ Residente do Serviço de \\ Coloproctologia do Hospital Universitário Cajuru - PUCPR; ${ }^{3}$ Residente do Serviço de Cirurgia Geral do Hospital \\ Universitário Cajuru - PUCPR; ${ }^{4}$ Membro do Serviço de Coloproctologia do Hospital Universitário Cajuru - PUCPR; \\ ${ }^{5}$ Membro do Serviço de Coloproctologia do Hospital Universitário Cajuru - PUCPR.
}

KOTZE PG; MARTINS JF; SELLA GV; ROCHA JG; MIRANDA EF. Necrose Pelvi-Perineal Pós-Radioterapia para Câncer de Próstata: Relato de Caso. Rev bras Coloproct, 2007;27(4): 452-455.

\begin{abstract}
RESUMO: Cerca de $75 \%$ dos pacientes irradiados para o tratamento do câncer de próstata desenvolverão sintomas proctológicos, como urgência, dor retal, tenesmo e sangramento. $O$ objetivo deste relato é descrever a ocorrência de necrose pelvi-perineal difusa associada à radioterapia para câncer de próstata, já que casos semelhantes não foram encontrados na literatura. Descrevese o caso de um paciente de 77 anos, com adenocarcinoma de próstata, que realizou radioterapia pélvica de 70 Gy como tratamento. Após 4 meses, identificou-se extensa lesão ulcerada de parede anterior do reto, extendendo-se superiormente até a junção retossigmoideana, com diagnóstico de proctite actínica, sem identificação de malignidade. $O$ paciente desenvolveu necrose da pele perineal, próstata, reto e musculatura do assoalho pélvico, que foi tratada com colostomia e extenso debridamento. Apresentou boa evolução pós-operatória e realizou tratamento com oxigenoterapia hiperbárica para cicatrização da ferida. A prevenção parece ser a melhor forma de tratamento de lesões actínicas em órgãos pélvicos. Pacientes submetidos a altas doses de irradiação encontram-se em risco real de desenvolvimento de lesões mais graves.
\end{abstract}

Descritores: Necrose; Períneo; Radioterapia; Neoplasias; Próstata.

\section{INTRODUÇÃO}

A radioterapia é uma das modalidades terapêuticas mais importantes no tratamento do câncer ${ }^{1}$. Na pelve, é usada em casos de neoplasias malignas de próstata, bexiga, colo do útero, reto e canal anal ${ }^{2,3}$. É possível minimizar a exposição dos tecidos sadios adjacentes à radiação pela anatomia favorável da região (proteção dos órgãos intra-abdominais), para se evitar lesões actínicas ${ }^{1}$. O reto é o órgão mais afetado no tratamento radioterápico das neoplasias nesta topografia ${ }^{1,2}$.

Cerca de $75 \%$ dos pacientes irradiados na pelve desenvolverão sintomas proctológicos, como urgência, dor retal, tenesmo e sangramento ${ }^{2}$. A proctite crônica pode surgir até dois anos após o tratamento, geralmente na forma de sangramento, com incidência de 3 a $20 \%$ dos casos ${ }^{4,5}$. Pode apresentar-se também com os mesmo sintomas da doença aguda, e mais raramente, com fístulas e estenoses.

Outras estruturas pélvicas, como a musculatura do assoalho pélvico, esfíncteres anais, próstata e pele podem ser afetadas pela radiação. A necrose é um evento raro, sendo poucos os casos descritos. Os relatos mais comuns são de necrose do reto isolada ${ }^{6,7}$. O objetivo deste relato é descrever a ocorrência de necrose pelvi-perineal difusa associada à radioterapia para câncer de próstata, já que casos semelhantes não foram encontrados na literatura.

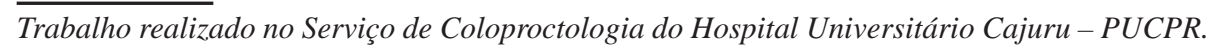

$\overline{\text { Recebido em 13/09/2007 }}$

Aceito para publicação em 08/10/2007 


\section{RELATO DO CASO}

I.A.Z., 77 anos, masculino, branco, natural de Joaçaba - SC, procedente de Curitiba - PR. Deu entrada no Ambulatório de Coloproctologia do Hospital Universitário Cajuru, em janeiro de 2007, com queixa de sangramento abundante por via anal, dor pélvica profunda e tenesmo com 30 dias de evolução. A dor era de forte intensidade, o que o impedia de sentar-se. Apresentava diarréia sanguinolenta, cerca de 3 a 4 episódios por dia, associada a antecedentes de distúrbios urinários. Tratado por 20 anos de hiperplasia prostática benigna. Foi diagnosticado em 2004 com adenocarcinoma de próstata. Em maio de 2005 foi submetido à orquiectomia bilateral e cistostomia. Iniciou radioterapia em junho de 2006 com término em setembro de 2006. A dose total de radiação foi de $70 \mathrm{~Gy}$, aplicada com acelerador linear de $4 \mathrm{mV}$. Em tratamento clínico para hipertensão arterial, negava outras patologias. Negava etilismo ou tabagismo. Negava história familiar prévia de qualquer tipo de câncer. Referia história de angioplastia de artérias coronárias há 7 anos.

Ao exame apresentava-se em mal estado geral, palidez muco-cutânea, abdome escavado, com cistotomia suprapúbica sem complicações. Apresentava inspeção normal ao exame proctológico. Ao toque retal apresentava extensa massa endurecida na parede anterior do reto, superfície irregular, acompanhado de extrema dor. A retossigmoidoscopia rígida não foi realizada por este motivo.

O paciente foi encaminhado para colonoscopia, que demonstrou extensa lesão ulcerada de parede anterior do reto, extendendo-se superiormente até a junção

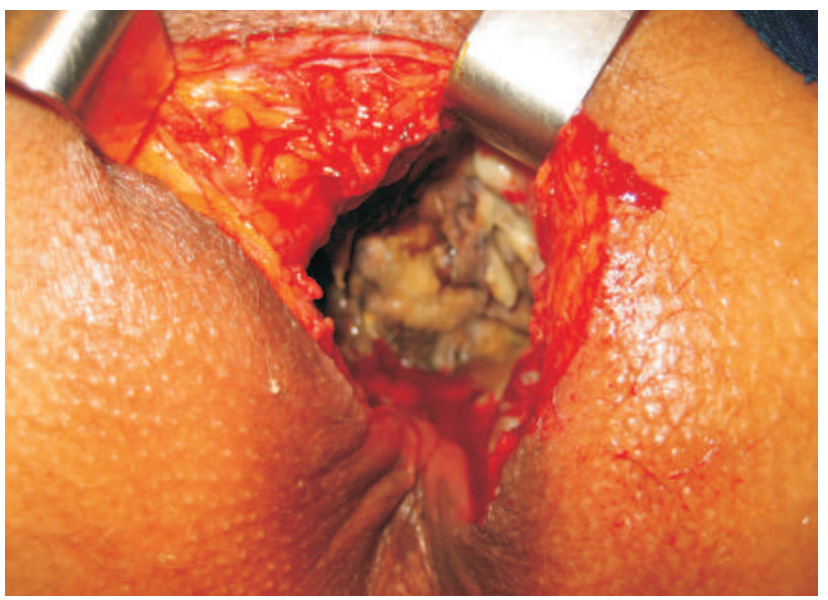

Figura 1 - Aspecto operatório do debridamento: necrose perineal profunda. retossigmoideana, que impediu a progressão do aparelho. Foram colhidas biópsias que demonstraram proctite actínica, sem identificação de malignidade. Foi realizado enema opaco para análise do cólon proximal, que demonstrou estreitamento da luz do sigmóide por inflamação.

Persistiu com sangramento nos dias subseqüentes, sendo internado por sepse e anemia pelo Serviço de Geriatria do referido hospital, com necessidade de transfusões sangüíneas múltiplas. Foi feito diagnóstico de pneumonia e sepse urinária. Nesta ocasião o paciente iniciou com quadro de incontinência fecal, e o exame proctológico identificou pequena ferida perineal com saída de secreção purulenta. Hipotonia esfincteriana foi evidenciada ao toque retal, com aparente dano na porção anterior da musculatura esfincteriana externa.

Após o término da antibioticoterapia e melhora do estado geral, o paciente foi submetido à colostomia em alça do cólon transverso com anestesia local e sedação e debridamento da ferida perineal. Durante o ato operatório, observou-se extensa necrose da musculatura do assoalho pélvico, esfíncteres anais, próstata e parede anterior do reto (figura 1). Realizou-se debridamento extenso destas estruturas. Apresentou evolução satisfatória, sem queda do hematócrito. Iniciou oxigenoterapia hiperbárica 48 horas após o debridamento. Em 2 semanas houve melhora da ferida perineal e identificou-se prolapso da boca distal da colostomia do transverso. Devido à dificuldade no manuseio das placas da estomatoterapia, foi submetido à correção do prolapso e transformação da colostomia em alça para terminal. Apresentou boa evolução pós-operatória e realizou tratamento com oxigenoterapia hiperbárica para acelerar a cicatrização da ferida perineal (figura 2).

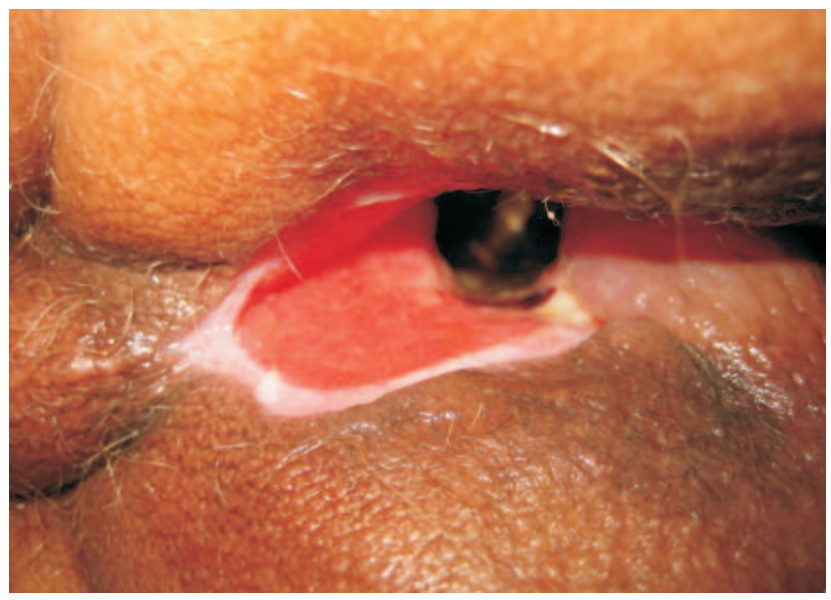

Figura 2 - Aspecto da ferida operatória após 20 sessões de Oxigenoterapia Hiperbárica. 


\section{DISCUSSÃO}

A incidência da proctite actínica tem aumentado com as maiores indicações da radioterapia para o câncer pélvico. Os sintomas pélvicos ocorrem em 75 \% dos casos após a radioterapia para o câncer de próstata, com queixas de urgência evacuatória, tenesmo, dor retal e sangramento ${ }^{2}$. A proctite crônica ocorre em 3 a 20\% dos casos, geralmente manifestando-se como sangramento retal ${ }^{4,5}$. Tal sintoma pode variar desde pequenas quantidades (forma intermitente) até perdas volumosas de sangue, com necessidade de transfusões sangüíneas periódicas ${ }^{1}$.

A radiação causa liberação de radicais livres de oxigênio e causa lesão do DNA, RNA e da parede celular. Afeta principalmente células com altas taxas de mitose, como é o caso das células da mucosa intestinal ${ }^{1}$.

As lesões agudas caracterizam-se pela presença de edema pálido da mucosa, sem alterações submucosas, com espessamento e fibrose da lâmina basal ${ }^{1}$. No caso de lesões crônicas, há fibrose do tecido conectivo e alterações vasculares, com espessamento da camada íntima dos vasos submucosos. Isto resulta em uma isquemia relativa, havendo formação de telangectasias pelos capilares da mucosa, com maior propensão ao sangramento ${ }^{1,7}$. Se a isquemia for mais severa, pode haver formação de úlceras mucosas, perfuração ou fístulas. Após 1 a 2 anos há contração máxima da fibrose, levando à exacerbação dos sintomas ${ }^{1}$.

No caso relatado o sangramento foi o sintoma principal. Chama atenção a rápida ocorrência dos sintomas após o termino da radioterapia.

Pode haver maior gravidade nas lesões actínicas em pacientes hipertensos, diabéticos, ou com doença cerebrovascular, assim como naqueles com cirurgias abdominais prévias, conforme mostram alguns estudos ${ }^{1}$. O dano tissular tende a ser mais acentuado, e mais estruturas podem ser lesadas nestes pacientes. Apesar de compensado clinicamente, o paciente descrito apresentava hipertensão arterial sistêmica, o que pode ter contribuído para o avançado grau da lesão e necrose das múltiplas estruturas.

Além disso, sabe-se que tratamentos radioterápicos com dosagem abaixo de 45 Gy raramente causam complicações actínicas nos órgãos pélvicos ${ }^{1,4}$. Por outro lado, pacientes submetidos à irradiação em torno de 75 Gy (dose máxima de radiação prescrita para a pelve) apresentam complicações mais severas em cerca de $60 \%$ dos casos ${ }^{4}$. Tal fato, possivelmente, explique a extensa necrose pelvi-perineal do caso em discussão.

O diagnóstico da proctite é feito por colonoscopia, já que geralmente o calibre do reto e do sigmóide está reduzido ${ }^{1,4,5}$. O sigmóide encontra-se comumente fixo, dificultando a passagem de qualquer tipo de aparelhagem endoscópica, rígida ou flexível. O exame permite o diagnóstico de lesões mucosas, biópsias e a identificação de possíveis lesões colônicas sincrônicas. O enema opaco deve ser realizado na impossibilidade de passagem do colonoscópio. Pode ser útil nos casos suspeitos de fístulas e em estenoses do sigmóide e do reto para estudo do restante do cólon ${ }^{1}$. A tomografia computadorizada e o PET-CT são usados frequientemente para o diagnóstico diferencial com recidiva da doença primária ${ }^{1}$.

A colonoscopia, no presente relato, não pôde ser realizada na sua totalidade devido a estas freqüientes alterações inflamatórias anteriormente discutidas. $\mathrm{O}$ enema opaco identificou de forma evidente estes achados.

As formas leves de proctite actínica são tratadas com uso tópico de derivados do 5-ASA, corticóides e formalina ${ }^{1,4,5}$. Outras formas de tratamento empregadas são a fulguração com plasma de argônio e a cauterização bipolar ${ }^{1,5}$.

A oxigenoterapia hiperbárica apresenta bons resultados em casos selecionados ${ }^{4}$. Geralmente é indicada em casos de sangramento, com bons resultados na remissão dos sintomas. No caso descrito, a indicação do método foi para cicatrização mais rápida e controle da infecção da extensa ferida perineal resultante do debridamento.

O tratamento cirúrgico fica reservado para situações de intratabilidade clínica, como fístulas retovaginais, sangramento que não responde à terapia endoscópica, ou em casos de necrose ${ }^{1,5}$. Pode-se optar por ressecção do segmento acometido com ou sem anastomose primária, utilizando desvios do trânsito proximal quando necessário ${ }^{1,3,5}$.

As necroses do reto descritas na literatura são usualmente tratadas com enemas de corticóides e desvio do trânsito proximal, com ou sem ressecção ${ }^{6,7}$. Destes, a melhor opção é a colostomia em alça do sigmóide, pelas menores taxas de complicações e maior facilidade técnica de confecção ${ }^{6}$. Entretanto, nos casos de fixação e inflamação do sigmóide, tal opção 
Rev bras Coloproct Outubro/Dezembro, 2007 não é factível. Neste caso pode-se optar por ileostomia em alça ou colostomia em alça do transverso. Estas foram as razões que justificaram o tipo de colostomia empregada no caso descrito.

Com o avanço nas técnicas de radioterapia pélvica deve haver diminuição da incidência de complicações locais de natureza actínica. As técnicas mais novas desta modalidade terapêutica apresentam melhor distribuição da radiação por estudo tomográfico tridimensional, causando menor dano às estruturas adjacentes ao órgão-alvo ${ }^{8}$.

Portanto, a prevenção parece ser a melhor forma de tratamento de lesões actínicas em órgãos pélvicos. Pacientes submetidos a altas doses de irradiação, encontram-se em risco real de desenvolvimento de lesões mais graves. É necessário um alto grau de suspeição no diagnóstico de feridas perineais, e exames proctológicos freqüentes devem ser realizados.

\begin{abstract}
Around 75\% of the patients submitted to radiotherapy for prostate cancer will develop anorectal symptoms, such as fecal urgency, bleeding, rectal pain and tenesmus. Perineal necrosis is a very rare event in these cases. The purpose of this report is the description of a diffuse perineal necrosis due to radiotherapy for the treatment of prostate cancer. This is a report of a 77year old male, submitted to radiotherapy with $70 \mathrm{~Gy}$ of pelvic radiation for prostate cancer treatment. He came to outpatient practice after 4 months with anorectal complaints. Further investigation revealed severe radiation proctitis, with a perineal wound and external anal sphincter damage. The patient was submitted to a loop transverse colostomy with extended perineal debulking due to diffuse necrosis of pelvic structures, such as prostate, pelvic floor muscles and anterior rectal wall. Hyperbaric oxygen therapy was started for the extended perineal wound, with success. Prevention is the key to avoid radiation damage in pelvic organs. Doses above $70 \mathrm{~Gy}$ are associated with high risk of associated pelvic complications. The treatment of diffuse perineal necrosis must be prompt and aggressive. Fecal diversion is mandatory in cases with extended sphincter destruction.
\end{abstract}

Key words: Necrosis; Perineum; Radiotherapy; Neoplasms; Prostate.

\title{
REFERÊNCIAS
}

1. Johnston, MJ; Robertson, GM; Frizelle, FA. Management of Late Complications of Pelvic Radiation in the rectum and Anus. Dis Colon Rectum 2003; 46, (2): p 247-256

2. Kushwaha, RS; Hayne, D; Vaizey, CJ et al. Physiologic Changes of the Anorectum After Pelvic radiotherapy for the Treatment of Prostate and Bladder Cancer. Dis Colon Rectum 2004; 46, (9): p 1182-1188.

3. Lucarotti, ME; Mountford, RA; Bartolo, DCC. Surgical Management of Intestinal Radiation Injury. Dis Colon Rectum 1991; 34, (10): p 865-869.

4. Bem, MD; Bem, S; Singh, A. Use of Hyperbaric Oxygen Chamber in the Management of Radiation-Related Complications of the Anorectal Region. Dis Colon Rectum 2003; 43, (10): p 1435-1438.

5. Bonis, PAL; Nostrant, TT. Diagnosis and Treatment of Chronic radiation Proctitis. 2006. Available from: URL: http:/ /www.uptodate.com.
6. Quan, SHQ; O’Kelly, PJ. Rectal Necrosis Following external Radiation Therapy for Carcinoma of the Prostate: Report of a Case. Dis Colon Rectum 1975;18, (1): p 64-66.

7. Tomori, H; Yasuda, T; Shiraishi, M et al. radiation-Associated Ischemic Coloproctitis: Report of Two Cases. Surgery Today 1999: p 1088-1092.

8. Taussky, D; Schneider, U; Rousson, V; Pescia, R. Toxicity Correlated to Dose-Volume Histograms of the Rectum in Radiotherapy of the Prostate. American Journal of Clinical Oncology 2003; 26, (5): p 144-149.

Endereço para correspondência:

PAULO GUSTAVO KOTZE

Rua Jaime Balão, 975 - ap. 106 - Curitiba - PR

CEP: 80040-340

FAX: 41 3253-7838

E-mail:pgkotze@ hotmail.com 